\title{
Brain Atrophy, Anti-Smooth Muscle Antibody and Cognitive Impairment: An Association Study
}

\author{
Paroni Giulia ${ }^{1 *}$, Lauriola Michele ${ }^{1}$, Fontana Andrea ${ }^{2}, D^{\prime}$ Onofrio Grazia ${ }^{1}$, Ciccone Filomena ${ }^{1}$, \\ Paris Francesco ${ }^{1}$, Cascavilla Leandro', Urbano Maria ${ }^{1}$, Gravina Carolina ${ }^{1}$, Copetti \\ Massimiliano $^{2}$, Greco Antonio ${ }^{1}$ \\ 1Gerontology-Geriatric Research Laboratory and Geriatric Unit, Department of Medical Sciences, I.R.C.C.S.
"Casa Sollievo della Sofferenza", 71013 San Giovanni Rotondo, Foggia, Italy
${ }^{2}$ Unit of Biostatistics, I.R.C.C.S. "Casa Sollievo della Sofferenza",71013 San Giovanni Rotondo Foggia, Italy
}

[Received August 20, 2015; Revised November 11, 2015; Accepted November 24, 2015]

\begin{abstract}
Cortical atrophy, neuronal loss, beta-amyloid deposition, neuritic plaques, and neurofibrillary tangles are neuropathological key features in the Alzheimer's disease (AD). Antibodies against beta-amyloid, neurotransmitters, microvascular endothelium components and microglial cells have been detected in AD serum suggesting that AD could be another autoimmune disease and provides a link between vascular pathology, endothelium dysfunction and neuronal cells death. Aim of the present study was to evaluate the association between autoantibody profile and cognitive impairment in geriatric patients, accounting for ApoE genotype as a potential confounding factor. Three hundred and forty-four geriatric patients, attending the clinic for the cognitive decline, underwent a biochemical and immunological profile, chest $\mathrm{X}$-ray, cerebral computed tomography scan and complete cognitive evaluation. All patients were also screened for the ApoE genotype. A significantly higher prevalence of Anti-Smooth Muscle Antibody (ASMA) positivity was found in 89/204 (43.63\%) patients with diagnosed neuroradiological signs of cerebral atrophy compared with 15/140 $(\mathbf{1 0 . 7 1 \%})$ patients without the condition $(\mathbf{p}<\mathbf{0 . 0 0 1})$. Multivariable logistic model evidenced that such association was independent of patient's age, gender and Mini-Mental State Examination (OR=8.25, 95\% CI: 4.26-15.99) and achieved a good discriminatory power (c-statistic=0.783). Results were also independent of ApoE genotype, which resulted not associated both with the presence of brain atrophy and with the presence of ASMA positivity. Our results shows a strong association between brain atrophy and ASMA positivity and are consistent with several studies that focused attention on the mechanisms of endothelial immune response in the development of dementia.
\end{abstract}

Key words: brain atrophy, anti-smooth muscle antibody, cognitive impairment

Interaction between the immune and the nervous systems is bidirectional and occur under both physiological and pathological conditions. The effects of the aging process on the constituents of both these systems result in important functional changes in their interactions; such effects, in turn, alter susceptibility to autoimmune, neoplastic and degenerative disease of the nervous system.

Cortical atrophy, neuronal loss, beta-amyloid deposition, neuritic plaques, and neurofibrillary tangles are neuropathological key features in the Alzheimer's disease [1]. Amyloid deposits have been observed in microvessels and are often associated with degenerating endothelium, damaged smooth muscle cells and pericytes, and are associated with various abnormal basement membrane alterations which are all components of bloodbrain-barrier (BBB) damage. Then the major pathological role of beta-amyloid in $\mathrm{AD}$ may be to induce vascular and $\mathrm{BBB}$ function damage [2-4]. Impairment of BBB function can occur in conditions that are commonly associated with aging, such as atherosclerosis, hypertension, cerebrovascular ischemia and stroke; all of which have

*Correspondence should be addressed to: Giulia Paroni, PhD, Department of Medical Sciences, I.R.C.C.S. "Casa Sollievo della Sofferenza", San Giovanni Rotondo, Foggia, Italy. Email address: giulia.paroni@operapadrepio.it

Copyright: @ 2016 Paroni G, et al. This is an open-access article distributed under the terms of the Creative Commons Attribution License, which permits unrestricted use, distribution, and reproduction in any medium, provided the original author and source are credited. 
been found to be risk factors for $\mathrm{AD}$. In addition, altered blood brain barrier has been associated with mutations of the apolipoprotein E (ApoE) gene [5,6]. Current concepts regarding the pathogenesis of $\mathrm{AD}$ include the participation of mechanism of endothelial dysfunction associated to inflammatory and autoimmune components $[7,8]$. Autoimmunity can be involved in many human diseases, and even though the causes of the autoimmune disorders are unknown, the specific targets of the autoantibodies characterize each autoimmune disease. Autoantibodies can also affect the central nervous system (CNS) reacting with neurons in neurological diseases including Huntington's chorea [9], Sydenham's chorea [10], cerebral lupus [11,12], multiple sclerosis [13,14], experimental allergic encephalomyelitis [15], Rasmussen's encephalitis [16,17] and recently in Alzheimer's disease $[18,19]$. Anti-neuronal autoantibodies have been detected in AD serum, but their significance still remains obscure and their use as diagnostic tools has partially been dismissed due to the presence of similar amounts of these antibodies in healthy donors [20]. Is already known that antibodies against betaamyloid are present in AD patients' serum and in nondemented individuals [21]. There is a growing evidence that lipid metabolism and oxidative stress may also participate in the pathogenesis of AD. Oxidized lowdensity lipoproteins (OxLDL) are also known to be highly immunogenic and induce systemic antibodies with important functional properties in health and disease [22]. Ganglioside GM1 tightly binds to beta-amyloid and may inhibit its conformational changes (from alpha-helix to beta-sheet). Several studies reported an increase in antiGM1 titers in the AD patients' serum as well as from other age-related dementias [23-24]. It is well known that during the progression of $\mathrm{AD}$ there is a global loss of neurotransmitters but there is a lack of significant data linking autoimmunity to loss of neurotransmitters in $\mathrm{AD}$ [25]. Autoantibodies to glutamate were detected in blood plasma from patients with AD. Importantly, plasma concentration of immune complexes and antibodies to serotonin and dopamine were higher in patients with $\mathrm{AD}$ compared to mentally healthy volunteers of the same age [26]. A great body of evidence exists about the fact that antibodies to microvascular endothelium might have a role in the $\mathrm{BBB}$ damage, inducing activation and/or apoptosis in endothelial cells; Delunardo et al. identified rabaptin 5 (RABPT5) as a new endothelial autoantigen in $A D$, recognized by serum IgG in $65 \%$ of patients with $A D$ [27]. Mruthinti et al. reported that anti-RAGE IgG titers were higher in AD-diabetic patients [28]. Serum anti-ATP synthase autoantibodies were detected in $38 \%$ of patients with AD. Antibodies directed against microglial cells were found in serum and CSF of AD patients [29]. Serum antibodies to spectrin, peroxidise, thyroglobulin and myelin basic protein are significantly increased in patients with AD. In summary, these data in the context of the underlying mechanisms of many autoimmune diseases, indicated that $\mathrm{AD}$ could be another autoimmune disease and provides a link between vascular pathology, endothelium dysfunction and neuronal cells death [3032]. Aim of the present study was to evaluate the association between autoantibody profile and cognitive impairment according to age.

\section{MATERIALS AND METHODS}

\section{Patient recruitment}

This was a monocentric cross sectional study fulfilling the Declaration of Helsinki (availabe at: www.wma.net/en), the guidelines for Good Clinical Practice (available at: www.ema.europa.eu) the Strengthening the Reporting of Observational Studies in Epidemiology (STROBE) guidelines (available at: www.strobe-statement.org) and the National Institute for Health and Clinical Excellence (NICE) requirements (available at: www.nice.org.uk). The approval of the study for experiments using human subjects was obtained from the local Ethics Committees on human experimentation. Written informed consent for research was obtained from each patient or from relatives/legal guardian in the case of critically disabled demented patients prior to participation in the study. All patients included in this study were Caucasians, with most individuals living in Central and Southern Italy from at least two generations. All subjects included in this study were selected among patients consecutively attending the clinic for cognitive decline of the Geriatrics Unit of the Istituto di Ricovero e Cura a Carattere Scientifico (IRCCS) "Casa Sollievo della Sofferenza" (Italy) from July 2012 to July 2014.

\section{Inclusion/exclusion criteria}

Inclusion criteria were: 1) age $\geq 65$ years as we are evaluating a geriatric population; 2) all kind of cognitive status (i.e. no cognitive impairment (CTRL), Alzheimer Disease (AD), Depression, mild cognitive impairment (MCI), Parkinson's Disease (PD), diagnosis of vascular dementia $(\mathrm{VaD}), 3)$ given informed consent for research. Exclusion criteria were: 1) diagnosis of mixed dementia (MxD); 2) presence of immuno-rheumatological diseases; 3 ) presence of serious comorbidity, tumors, other diseases or physiological status (ascertained blood infections, vitamin B12 deficiency, anemia, disorders of the thyroid, kidneys), that could be causally affect to cognitive function; 4) history of alcohol or drug abuse; 5) head trauma; 6) clinical, biochemical and radiological findings, consistent with liver and/or lung disease). 


\section{Clinical and instrumental assessment}

All patients attending the clinic for the cognitive decline, underwent a standard diagnostic tool. Briefly, a physical examination, electrocardiogram, venous blood sampling for biochemical profile, chest X-ray, cerebral computed tomography scan and complete cognitive evaluation were assessed.

Blood tests include complete blood count, electrolytes, renal and liver function, lipid profile, glycaemia, homocysteine, vitamin B12, folate, thyroid function, total protein electrophoresis, serum calcium, ESR, CRP and autoantibody profile (i.e. Anti-nuclear antibody - ANA, Anti-mitochondrial antibody - AMA, Anti-smooth muscle antibody - ASMA, Anticitrullinated protein antibody - APCA, assessed by semiquantitative determination (Immunofluorece BIO RAD Kallestad).

\section{Cognitive-functional evaluation and diagnosis}

Baseline demographic and clinical characteristics were collected by a structured interview, a clinical evaluation and a review of records from patient's general practitioners.

In all patients, cognitive status was screened by means of the Mini-Mental State Examination (MMSE) [33] the Alzheimer's Disease Assessment Scale Cognitive Section (ADAS-Cog) [34], and the Clinical Dementia Rating scale (CDR) [35]. Dementia (CDR 1+) was confirmed and diagnosed by the Diagnostic and Statistical Manual of Mental Disorders, fourth edition (DMS-IV), whereas diagnosis of questionable dementia (QD) was made according to a CDR value of $0.5+$ [36]. Diagnosis of mild cognitive impairment (MCI) was made, according to the Petersen criteria [37], in subjects with CDR 0.5+ and an MMSE value from 24 to 27. Diagnosis of possible/probable $\mathrm{AD}$ was made according to the criteria of the National Institute of Neurological and Communicative Disorders and Stroke - Alzheimer's Disease and Related Disorders Association Work Group (NINCDS-ADRDA) [38]. Diagnosis of Parkinson's disease was made according to the NICE guideline for diagnosis and treatment of Parkinson's disease. Diagnosis of vascular dementia $(\mathrm{VaD})$ was made according to the criteria of the National Institute of Neurological Disorders and Stroke - Association Internationale pour la Recherche et l'Enseignement en Neurosciences Work Group (NINDS-AIREN) [39]. Differential diagnosis between $\mathrm{AD}$ and $\mathrm{VaD}$ was also based on the Hachinski Ischemic Score to address unclear $\mathrm{AD} / \mathrm{VaD}$ diagnoses [40]. In particular scores $\leq 4$ were considered as probable $\mathrm{AD}$, scores $\geq 7$ were included into the $\mathrm{VaD}$ group. Scores between 5 and 6 were diagnosed as mixed dementia
$(\mathrm{MxD})$ and were excluded from the study. Diagnosis of $\mathrm{AD}$ or $\mathrm{VaD}$ was always supported by neuroimaging evidences (computed tomography scan and/or nuclear magnetic resonance). In particular, the presence of multiple cortical/subcortical infarcts or an infarct in a strategic area such as the thalamus or temporal lobe and/or lesions of the white matter indicated probable $\mathrm{VaD}$. The absence of the above mentioned cerebrovascular lesions indicated AD. Functional status was evaluated using the Activities of Daily Living (ADL) index [41] and the Instrumental Activities of Daily Living (IADL) scale [42].

\section{Genetic analysis}

Genomic DNA was purified from fresh/frozen blood samples following salting-out method [43]. In the present study, for all patients we analyzed the $A P O E$ genotypes as previously described [44].

\section{Statistical Analysis}

Patients' characteristics were reported as mean \pm standard deviation (SD) and frequencies (column percentages) for continuous and categorical variables, respectively. Comparisons between patients with a diagnosed brain atrophy and those without a diagnosed brain atrophy were performed using two-sample $\mathrm{t}$ test and Pearson Chisquare test (or Fisher exact test as appropriate), for continuous and categorical variables, respectively. Normal distribution assumption was checked by means of Q-Q plot, Shapiro-Wilks and Kolmogorov-Smirnov tests. Associations between ASMA positivity and the presence of brain atrophy were assessed using both univariable and multivariable logistic regressions and results were reported as odds ratio (OR), along with their 95\% confidence intervals $(95 \% \mathrm{CI})$.

For multivariable analysis, the following adjustment covariates were considered: patients' age, gender, MMSE value, APOE genotype, neurological diagnosis (i.e. CTRL, VaD, MCI, PD, AD and depression). The stepwise variable selection criterion (significance level for entry into the model: $\mathrm{p}=0.10$, significance level for staying into the model: $\mathrm{p}=0.05$ ) was used to select, among all candidate covariates, the ones to be included into the final multivariable model. Models' discrimination, i.e. the ability to distinguish patients with diagnosed brain atrophy from patients without the diagnosed brain atrophy, was assessed by computing the concordance (or c) statistic using the models' predicted probabilities [45]. Comparison between c-statistics was carried out using DeLong's test [46]. Two-sided p-values $<0.05$ were considered statistically significant. All statistical analyses were performed using SAS Release 9.3 (SAS Institute, Cary, NC). 
Table 1. Demographic and clinical patients' characteristics (overall and according to the presence of brain atrophy)

\begin{tabular}{|c|c|c|c|c|}
\hline Variable & $\begin{array}{l}\text { All subjects } \\
(\mathrm{N}=344)\end{array}$ & $\begin{array}{l}\text { Without diagnosed } \\
\text { atrophy }(\mathrm{N}=140)\end{array}$ & $\begin{array}{l}\text { With diagnosed } \\
\text { atrophy }(N=204)\end{array}$ & $p$-value* \\
\hline Age (years) & $77.81 \pm 8.20$ & $75.19 \pm 8.69$ & $79.63 \pm 7.33$ & $<0.001$ \\
\hline Gender - N of males (\%) & $131(38.08)$ & $45(32.14)$ & $86(42.16)$ & 0.060 \\
\hline $\begin{array}{l}\text { Positivity for Anti-Smooth Muscle } \\
\text { Antibody - N (\%) }\end{array}$ & $104(30.23)$ & $15(10.71)$ & $89(43.63)$ & $<0.001$ \\
\hline $\begin{array}{l}\text { Mini-Mental State Examination } \\
\text { (MMSE) }\end{array}$ & $19.96 \pm 6.45$ & $21.43 \pm 5.75$ & $18.95 \pm 6.72$ & $<0.001$ \\
\hline $\begin{array}{l}\text { Number of patients with } \mathrm{MMSE}<25 \text { - } \\
\mathrm{N}(\%)\end{array}$ & $251(72.97)$ & $93(66.43)$ & $158(77.45)$ & 0.024 \\
\hline
\end{tabular}

*p-value from Pearson Chi-Square test and two-sample t-test for categorical and continuous variables, respectively.

\section{RESULTS}

A total of 344 eligible geriatric patients (131 males/213 females, with a mean age of $77.81 \pm 8.20$ years and a mean MMSE of $19.96 \pm 6.45$ ) were enrolled in this study. Neuroradiological signs of brain atrophy were found in $204(59.3 \%)$ patients. Demographic and clinical patients' characteristics (overall and according to the presence of brain atrophy) are summarized in Table 1.

A significantly higher prevalence of Anti-Smooth Muscle Antibody (ASMA) positivity was found in patients with brain atrophy compared to those without the condition (43.63\% vs. $10.71 \%, \mathrm{p}<0.001)$. The diagnostic accuracy of the ASMA positivity to predict a brain atrophy was characterized by a sensitivity of $46.3 \%$, a specificity of $89.3 \%$, a positive predictive value of $85.6 \%$ and a negative predictive value of $52.1 \%$. Moreover, patients with brain atrophy were significantly older than those without the condition $(79.63 \pm 7.33$ vs. $75.19 \pm 8.69$ years, $p<0.001)$ and had a significantly lower MMSE score $(18.95 \pm 6.72$ vs. $21.43 \pm 5.75, p<0.001)$.

In Table 2 patients are stratified on the basis of clinical diagnosis and genotype profile overall and according to the presence of brain atrophy. As expected, significantly higher prevalence of AD $(34.31 \%$ vs. $19.29 \%, p=0.002$ ) was found in patients with cerebral atrophy. No significant differences in ApoE genotype distribution were found.

Table 2. Patients' clinical diagnosis and genotype profile (overall and according to the presence of brain atrophy)

\begin{tabular}{|c|c|c|c|c|c|}
\hline Variable & Category & $\begin{array}{l}\text { All subjects } \\
(\mathrm{N}=\mathbf{3 4 4})\end{array}$ & $\begin{array}{c}\text { Without } \\
\text { diagnosed } \\
\text { atrophy }(\mathrm{N}= \\
140)\end{array}$ & $\begin{array}{l}\text { With diagnosed } \\
\text { atrophy } \\
(\mathrm{N}=\mathbf{2 0 4})\end{array}$ & $p$-value* \\
\hline \multirow{6}{*}{ Diagnosis - N (\%) } & No cognitive impairment & $22(6.40)$ & $8(5.71)$ & $14(6.86)$ & 0.669 \\
\hline & Alzheimer disease & $97(28.20)$ & $27(19.29)$ & $70(34.31)$ & 0.002 \\
\hline & Depression & $92(26.74)$ & $53(37.86)$ & $39(19.12)$ & 0.001 \\
\hline & Mild Cognitive Impairment & $90(26.16)$ & $37(26.43)$ & $53(25.98)$ & 0.926 \\
\hline & Parkinson's disease & $12(3.49)$ & $5(3.57)$ & $7(3.43)$ & 0.945 \\
\hline & Vascular dementia & $31(9.01)$ & $10(7.14)$ & $21(10.29)$ & 0.316 \\
\hline \multirow{7}{*}{ APOE - N (\%) } & Missing values (n) & 3 & 1 & 2 & \\
\hline & $\mathrm{e} 2 / \mathrm{e} 2$ & $2(0.59)$ & $0(0.00)$ & $2(0.99)$ & $0.516^{\#}$ \\
\hline & $\mathrm{e} 2 / \mathrm{e} 3$ & $22(6.45)$ & $6(4.32)$ & $16(7.92)$ & 0.183 \\
\hline & $\mathrm{e} 2 / \mathrm{e} 4$ & $3(0.88)$ & $1(0.72)$ & $2(0.99)$ & $1.000^{\#}$ \\
\hline & $\mathrm{e} 3 / \mathrm{e} 3$ & $208(61.00)$ & $88(63.31)$ & $120(59.41)$ & 0.468 \\
\hline & e3/e4 & $91(26.69)$ & $36(25.90)$ & $55(27.23)$ & 0.785 \\
\hline & $\mathrm{e} 4 / \mathrm{e} 4$ & $15(4.40)$ & $8(5.76)$ & $7(3.47)$ & 0.311 \\
\hline
\end{tabular}

$* p$-value from Pearson Chi-Square test and two-sample t-test for categorical and continuous variables, respectively.

$\# p$-value from Fisher exact test. 
Table 3 Results from univariable and multivariable logistic models, in the evaluation of the association between positivity to Anti-Smooth Muscle Antibody and the presence of brain atrophy

\begin{tabular}{llll}
\hline \multicolumn{1}{c}{ Model } & \multicolumn{1}{c}{ OR $(\mathbf{9 5 \%} \mathbf{C I})^{*}$} & \multicolumn{1}{c}{$\boldsymbol{p}$-value } & \multicolumn{1}{c}{ c-statistic $(\mathbf{9 5 \%} \mathbf{C I})^{\wedge}$} \\
\hline Univariable & $6.447(3.529-11.780)$ & $<0.001$ & $0.665(0.622-0.707)$ \\
Multivariable $^{\#}$ & $8.250(4.257-15.986)$ & $<0.001$ & $0.783(0.734-0.831)$ \\
\hline
\end{tabular}

*OR: Odds ratio along with their $95 \%$ confidence interval $(95 \% \mathrm{CI}) ;{ }^{\wedge} \mathrm{C}$-statistic along with $95 \% \mathrm{CI}$;

\#Multivariable model adjusted for: age, gender and MMSE (stepwise selection criterion with significance level for entry into the model: $\mathrm{p}=0.10$ and significance level for staying into the model: $\mathrm{p}=0.05$ )

Results from univariable and multivariable logistic regressions are reported in Table 3. As mentioned above, the presence of ASMA positivity was significantly associated to the presence of brain atrophy in the univariable analysis (OR=6.45, 95\%CI: 3.53-11.78, $p<0.001)$, achieving a fair overall discriminatory power $(\mathrm{c}=0.665)$. This association was also confirmed by the multivariable analysis $(\mathrm{OR}=8.25$, 95\% CI: 4.26-15.99, $\mathrm{p}<0.001$ ), where the following adjustment covariates were selected and included into the logistic regression: age, gender and MMSE. Such multivariable model achieved a good discriminatory power $(c=0.783)$ which was significantly higher than $\mathrm{c}=0.665$, from univariable model $(p<0.001)$. Furthermore, such results were independent by the ApoE genotype, which resulted not associated both with the presence of brain atrophy and with the presence of ASMA positivity.

\section{DISCUSSION}

An endothelial dysfunction, in many diseases, including chronic renal failure, heart failure, hypertension, diabetes, and immunologic diseases has been demonstrated [47-50] but its role in developing cognitive impairment is unknown and of increasing interest [51]. In addition, recent data have shown that endothelial function is impaired in $\mathrm{AD}$ patients, suggesting that such dysfunction might represent a link between vascular and beta-amyloid hypothesis of Alzheimer's disease [52-54]. The endothelium is a monolayer of endothelial cells lining the lumen of the vascular beds and is mechanically and metabolically located, separating the vascular wall from the circulation and the blood components [55]. Brain capillaries are normally dynamic, cylindrical tubes that are lined by endothelial cells with tight junctions, a basement membrane and, at irregular intervals, by pericytes [56,57]. Evidences suggest that pericytes may play a role in the regulation of blood flow by their contractile response and supporting this notion is the presence of myosin, actin and tropomyosin within pericytes [58,59]. Anti Smooth Muscle Antibodies (ASMA) react with actomyosin and different antigens of smooth muscles that constitute the cell cytoskeleton. ASMA, not species specific, are almost exclusively IgG, more rarely IgM. These antibodies can be detected with techniques of indirect immunofluorescence or, more recently, with fluorimetric immunoassay techniques $[60,61]$. According to current knowledge, the anti-G actin are specific to chronic active hepatitis. These antibodies are associated with pathological conditions with a strong inflammatory and immunological component (chronic hepatitis, viral diseases and lung disease). Also are present in approximately 20-30\% of apparently healthy subjects, a situation in which it is not yet known the significance of their presence.

The autoantibody profile observed in patients enrolled, showed that positivity for ASMA was greater in people with diagnosed atrophy as compared to those who did not present this abnormality. This difference was present regardless the level of cognitive impairment a shown in Table 1. Table 2 showed that cognitive status distribution was substantially related to the presence/absence of diagnosed brain atrophy and as expected brain atrophy was greater in AD. Moreover, ApoE polymorphism (a well-known risk factor for AD) didn't show any difference according to presence/absence of brain atrophy. Table 3 strongly evidenced the association between asma profile and brain atrophy both in univariate and multivariate approach.

A recent study indicates that Alzheimer's disease is a vascular disorder with neurodegenerative consequences [62]. Critically Attained Threshold of Cerebral Hypoperfusion (CATCH) is a haemodinamic microcirculatory insufficiency that destabilize neurons, synapses, neurotransmission with consequent neurodegenerative state characterized by the formation of senile plaques, neurofibrillary tangles and amyloid angiopathy [63]. Clinical evidence suggests that are fundamental in the development of CATCH duration and severity of hypoperfusion and the age of subjects. Pathological studies showed that brain capillaries in AD develop basement membrane thickening, pericyte degeneration, endothelial cell shape changes, and luminal buckling. These pathological changes cause altered 
microvascular blood flow and lower concentrations of glucose and oxygen in neuronal targets, creating an energy crisis at the mitochondrial level that causes unbalanced energy system in brain [64]. At present the major question is: how these vascular changes leading to chronic hypoperfusion cause neurodegeneration? Our results are in agreement with the growing evidences that there is a link between inflammation, endothelial dysfunction, brain immune system and pathogenesis of dementia. Moreover, accumulation and infiltration of activated immune cells have been well documented in the $\mathrm{AD}$ brain in addition to classical neuropathological signs i.e. amyloid plaques and NFT $[65,66]$. Clustering of activated microglia [67] and astrocytes is observed in the $\mathrm{AD}$ brain, associated with upregulated expression of a variety of inflammatory cytokines, including interleukin1 (IL-1) [68], interleukin-6 (IL-6) [69], tumor necrosis factor- $\alpha$ (TNF- $\alpha$ ) [70], and transforming growth factor- $\beta$ (TGF- $\beta$ ) [71]. Moreover, innate immune receptors, such as toll-like receptor and lipopolysaccharide (LPS) receptor (CD 14), are upregulated in the human AD brain [65]. Than, it has been shown that some markers of glial activation are elevated even before the development of amyloid deposition, implying that inflammation precedes typical AD neuropathological changes and has some causative effect in AD pathogenesis [72]. Our results lead us to assert that ASMA positivity explain only brain atrophy maybe as a consequence of endothelium damage. The usefulness of our results is to identify ASMA positivity as a potential risk factor of brain atrophy. As it is well known, this clinical condition can be a prelude to cognitive impairment. For this reason, it seems reasonable to propose ASMA profile as a tool to screen population at risk of developing cognitive impairment during aging process in a large cohort study.

\section{Acknowledgements}

All financial and material support for this research were provided by grants from Ministero della Salute, IRCCS Research Program 2012-2014 Line 2: "Malattie di rilevanza sociale" and all the authors don't have any conflict of interest.

\section{Conflicts of Interest}

All authors agree with the presented findings, have contributed to the work and declare no conflict of interest.

\section{References}

[1] Colasanti T, Barbati C, Rosano G, Malorni W, Ortona E (2010). Autoantibodies in patients with Alzheimer's disease: pathogenetic role and potentialuse as biomarkers of disease progression. Autoimmunity Reviews, 9(12):807-811.

[2] Moorandian D (1998). Effect of aging on the blood-brain barrier. Neuro Aging, 9:31-9.

[3] Claudio L (1996). Ultrastructural features of the bloodbrain barrier in biopsy tissue from Alzheimer's disease patients. Acta Neuropathol, 91:6-14.

[4] Thomas T, Thomas G, McLendon C, Sutton T, Mullan M (1996). $\beta$-Amyloid-mediated vasoactivity and vascular endothelial damage. Nature, 380:168-71.

[5] Hofman A, Ott A, Breteler MM, Bots ML, Slooter AJ, van Harskamp F, et al (1997). Atherosclerosis, apoliportotein E, and Prevalence of dementia, and Alzheimer's disease in the Rotterdam study. Lancet, 349:151-4.

[6] Gomez-Isla T, West HL, Rebeck GW, Harr SD, Growdon JH, Locascio JJ, et al (1996). Clinical and pathological correlates of Apolipoprotein E e4 in Alzheimer's disease. Ann Neurol, 39:62-70.

[7] D'Andrea MR (2005). Add Alzheimer's disease to the list of autoimmune diseases. Med Hypotheses, 64:458-63.

[8] Weiner HL, Selkoe DJ (2002). Inflammation and therapeutic vaccination in CNS diseases. Nature, 420:87984.

[9] Husby G, Lawrence L, Davis LE, Wedege E, Kokmen E, Williams RC (1977). Antibodies to human caudate nuclei neurons in Huntington's chorea. J Clin Invest, 59:922-32.

[10] Husby G, Vande Rijn I, Zabriskie JB, Abdin ZH, Williams RC (1976). Antibodies reacting with cytoplasm of subthalamic and caudate nuclei neurons in chorea and acute rheumatic fever. J Exp Med, 144:1094-110.

[11] Breshihan BM, Oliver M, Williams B, Hughes GRV (1979). An antineuronal antibody cross-reacting erythrocytes and lymphocytes in systematic lupus erythematosus. Arthritis Rheum, 22:313-20.

[12] Quismorio FP, Friou GJ (1972). Antibodies reactive with neurons in SLE patients with neuropsychiatric manifestations. Int Arch Allergy, 43:74-748.

[13] Noseworthy JH, Lucchinetti C, Roderiguez M, Weinshenker BG (2000). Medical progress: multiple sclerosis. N Engl J Med, 343:938-52.

[14] Storch MK, Piddlesden S, Haltia M, Iivanainen M, Morgan P, Lassmann H (1998). Multiple sclerosis: in situ evidence for anti-body and complement mediated demyelination. AnnNeurol, 43:465-571.

[15] Piddlesden SJ, Lassman H, Zimprich F, Morgon BP, Linington C (1993). The demyelinating potential of antibodies to myelin oligodendrocyte glycoprotein is related to their ability to fix complement. Am J Pathol, 143(2):555-64.

[16] Emmerling MR, Desiree Watson M, Raby CA, Spiegel K (2000). The role of complement in Alzheimer's disease pathology. Biochim Biophys Acta, 1502:158-71.

[17] Rogers SW, Anderws PI, Gahring LC, Whisenand T, Cauley K, Crain B, et al (1994). Autoantibodies to glutamate receptor GluR3 in Rasmussen's encephalitis. Science, 265:648-51.

[18] D'Andrea MR (2003). Evidence linking neuronal cell death to autoimmunity in Alzheimer's disease. Brain Res, 982:19-30.

[19] D'Andrea MR, Belkowski B (2004). Continual 
investigations of Ig-Positive neurons in Alzheimer disease tissues. Neuro Aging, 25(S2): S404.

[20] D'Andrea MR (2003). Evidence linking neuronal cell death to autoimmunity in Alzheimer's disease. Brain Res, 982:19-30.

[21] Szabo P, Relkin N, Weksler ME (2008). Natural human antibodies to amyloid beta peptide. Autoimmun Rev, 7:415-20.

[22] Binder CJ, Hörkkö S, Dewan A, Chang M, Kieu EP, Goodyear CS, et al (2003). Pneumococcal Vaccination decreases atherosclerotic lesion formation: molecular mimicry between Streptococcus pneumoniae and oxidized LDL. Nat Med, 9:736-743.

[23] Yanagisawa K, Odaka A, Suzuki N, Ihara Y (1995). GM1 ganglioside-bound amyloid ß-Protein (Aß): a possible form of pre amyloid in Alzheimer's disease. Nat Med, 1:1062-1066.

[24] Mandal PK, Pettegrew JW (2004). Alzheimer's disease: NMR studies of asialo (GM1) and trisialo (GT1b) ganglioside interactions with Abeta (1-40) peptide in a membrane mimic environment. Neurochem Res, 29:447453.

[25] Schott K, Wormstall H, Dietric M, Klein R, Batra A (1996). Autoantibodies reactivity in Serum of patients with Alzheimer's disease and other age-related dementias. Psychiatry Res, 59:251-254.

[26] Davydova TV, Voskresenskaya NI, Fomina VG, Vetrile LA, Doronina OA (2007). Induction of autoantibodies to glutamate in patients with Alzheimer's disease. Bull Exp Biol Med, 143:182-183.

[27] Delunardo F, Margutti P, Pontecorvo S, Colasanti T, Conti F, Riganò R, et al (2007). Screening of a microvascular endothelial cDNA library identifies rabaptin5 as novel autoantigen in Alzheimer's disease. $\mathrm{J}$ Neuroimmunol, 192:105-112.

[28] Mruthinti S, Schade RF, Harrell DU, Gulati NK, SwamyMruthinti S, Lee GP, et al (2006). Autoimmunity in Alzheimer's disease as evidenced by plasma immunoreactivity Against RAGE and Abeta 42: complication of diabetes. Curr Alzheimer Res, 3:229-235.

[29] Vacirca D, Delunardo F, Matarrese P, Colasanti T, Margutti P, Siracusano A, et al. (2010). Autoantibodies to the ATP synthase play a pathogenetic role in Alzheimer's disease. Neurobiol Aging, 33(4):753-766.

[30] Ounanian A, Guilbert B, Renversez JC, Seigneurin JM, Avrameas S (1990). Antibodies to viral antigens, xenoantigens, and autoantigens in Alzheimer's disease. $\mathbf{J}$ Clin Lab Anal, 4:367-375.

[31] Singh VK, Yang YY, Singh EA (1992). Immunoblot detection of antibodies to myelin basic proteinin Alzheimer's disease patients. Neurosci Lett, 147:25-28.

[32] Serot JM, Bene MC, Gobert B, Christmann D, Leheup B, Faure GC (1992). Antibodies to choroid plexus in senile dementia of Alzheimer's type. J Clin Pathol, 45:781-783.

[33] Folstein M, Folstein S, McHugh PR (1975). Minimental state: a practical method for grading the cognitive state of patients for the clinician. J Psychiatr Res, 12:189-198.

[34] Rosen WG, Mohs RC, Davis KL (1984). A new rating scale for Alzheimer's disease. Am J Psychiatry, 14:135664.
[35] Morris JC (1993). The Clinical Dementia Rating (CDR): current version and scoring rules. Neurology, 43:24122414.

[36] Seripa D, Franceschi M, D'Onofrio G, Panza F, Cascavilla $\mathrm{L}$, Paris F, et al (2008). Polymorphism $\mathrm{C}$ in the serotonin transporter gene (SLC6A4) in questionable dementia and Alzheimer's disease. Neurosci Lett, 438:335-339.

[37] Petersen RC, Doody R, Kurz A, Mohs RC, Morris JC, Rabins PV, et al (2001). Current concepts in mild cognitive impairment. Arch Neurol, 58: 1985-1992.

[38] McKhann G, Drachman D, Folstein M, Katzman R, Price D, Stadlan EM (1984). Clinical diagnosis of Alzheimer disease: report of the NINCDS-ADRDA work group under the auspices of Department of Health and Human Service Task Force on Alzheimer's disease. Neurology, 34: 939-944.

[39] Román GC, Tatemichi TK, Erkinjuntti T, Cummings JL, Masdeu JC, et al (1993). Vascular dementia: diagnostic criteria for research studies Report of the NINDS-AIREN International Workshop. Neurology, 43:250-260.

[40] Hachinski VC, Iliff LD, Zilhka E, Du Boulay GH, McAllister VL, Marshall J, et al (1975). Cerebral blood flow in dementia. Arch Neurol, 32: 632-637.

[41] Katz S, Ford AB, Moskowitz RW, Jackson BA, Jaffe MW (1963). Studies of illness in the aged: the index of ADL a standardized measure of biological and psychological function. JAMA, 185:914-919.

[42] Lawton MP, Brody EM (1969). Assessment of older people: self-maintaining and instrumental activities of daily living. Gerontologist, 9:179-186.

[43] Miller SA, Dykes DD, Polesky HF (1998). A simple salting out procedure for extracting DNA from human nucleated cells. Nucleic Acids Res, 16:1215.

[44] Seripa D, Signori E, Gravina C, Matera MG, Rinaldi M, Fazio VM (2006). Simple and effective determination of apolipoprotein E genotypes by positive/negative polymerase chain reaction products. Diagn Mol Pathol, 15:180-185.

[45] Harrell FE Jr editor. Regression Modeling Strategies: With Applications to Linear Models, Logistic Regression, and Survival Analysis. New York: Springer Series in Statistics; 2001

[46] DeLong ER, DeLong DM, Clarke Pearson DL (1988). Comparing the areas under two or more correlated receiver-operating characteristic curves; a nonparametric approach. Biometrics, 44:837-845.

[47] Johnstone MT, Creager SJ, Scales KM, et al (1993). Impaired endothelium dependent vasodilation in patients with insulin dependent diabetes mellitus. Circulation, 88:2510-2516.

[48] Panza JA, Quyyumi AA, Brush JE et al (1990). Abnormal endothelium dependent vascular relaxation in patients with essential hypertension. Nengl J Med, 323:22-27.

[49] Karadag O, Calguneri M, Atalar E, et al (2007). Novel cardiovascular risk factors and cardiac event predictors in female inactive systemic lupus erythematosus patients. Clin Rheumatol; 26: 695-699.

[50] Akdogan A, Calguneri M, Yavuz B, et al (2006). Are familial Mediterranean fever (FMF) patients at increased risk for atherosclerosis? Impaired endothelial function and 
increased intima media thickness are found in FMF. J Am Coll Cardiol, 48:2351-2353.

[51] Luchsinger JA, Reitz C, Honig LS, Tang MX, Sheas S, Mayeux R (2005). Aggregation of vascular risk factors and risk of incident Alzheimer disease. Neurology, 65:545-551.

[52] de la Torre JC (2010). Vacular risk factor detection and control may prevent Alzheimer's disease. Ageing Res Rev, 9: 218-225.

[53] Dede DS, Yavuz B, Yavuz BB, Cankurtaran M, Halil M, Ulger $Z$ et al (2007). Assessment of Endothelial Function in Alzheimer'scDisease: Is Alzheimer's disease a Vascular Disease? Jam Geriatr Soc, 55:1613-1617.

[54] Buee L, Hof PR, Delacourte A (1997). Brain microvascular changes in Alzheimer's disease and other dementias. Ann NY Acad Sci, 826:7-24.

[55] Bonetti PO, Lerman LO, Lerman A (2003). Endothelial dysfunction: A marker of atherosclerotic risk. Arterioscler Thromb Vasc Biol, 23:168-175.

[56] Pardridge WM (1999). Blood-brain barrier biology and methodology. J Neurovirol, 5:5556-69.

[57] Rhodin JAG (1980). Architecture of the vessel wall. In: Bohr DF, Somlyo AP, Sparks JR HV, Gieger SR, editors. Handbook of Physiology: The Cardiovascular System. Bethesda: The Williams and Wilkins Company, 1-31.

[58] Balabanov R, Dore-Duffy P (1998). Role of the CNS microvascular pericyte in the blood-brain barrier. J Neurosci Res, 53(6):637-644.

[59] Takahashi A, Park HK, Melgar MA (1997). Cerebral cortex blood flow and vascular smooth muscle contractility in a rat model of ischemia: a correlative laser Doppler flowmetric and scan in electron microscopic study. Acta Neuropathol, 93:354-368

[60] Zamanou A, Tsirogianni A, Terzoglou C, Balafas A, Economidou I, Lymberi P (2002). Anti-smooth muscle antibodies (ASMAs) and anti-cytoskeleton antibodies (ACTAs) in liver diseases: a comparison of classical indirect immunofluorescence with ELISA. J Clin Lab Anal, 16(4):194-201.

[61] Johanet C, Ballot E (2012). Auto-antibodies in autoimmune hepatitis: anti-smooth muscle antibodies (ASMA). Clin Res Hepatol Gastroenterol, 36:189-191.

[62] Aliev G (2002). Is non-genetic Alzheimer's disease a vascular disorder with neurodegenerative consequences? J Alzheimers Dis, 4(6):513-516.

[63] de la Torre JC, Stefano GB (2000). Evidence that Alzheimer's disease is a microvascular disorder: the role of constitutive nitric oxide. Brain Research Reviews, 34:119-136.

[64] Buee L, Hof PR, Bouras C, Delacourte A, Perl D, Norrison JH, Fillit HM (1994). Pathological alterations of the cerebral microvasculature in Alzheimer's disease and related demented disorders. Acta Neuro pathol, 87:469480.

[65] Letiembre M, Liu Y, Walter S, Hao W, Pfander T, Wrede A, et al. (2009). Screening of innate immune receptors in neurodegenerative diseases: a similar pattern. Neurobiol Aging, 30:759-768.

[66] Simard A, Soulet D, Gowing G, Julien JP, and Rivest S (2006). Bone marrow-derived microglia play a critical role in restricting senile plaque formation in Alzheimer's disease. Neuron, 49:489-502.

[67] Mrak RE, Sheng JG, Griffin WS (1996). Correlation of astrocytic S100 beta expression with dystrophic neuritis in amyloid plaques of Alzheimer's disease. J Neuropathol Exp Neurol, 55:273-279.

[68] Griffin WS, Sheng JG, Roberts GW, Mrak RE (1995). Interleukin-1 expression in different plaque types in Alzheimer's disease: significance in plaque evolution. $\mathbf{J}$ Neuropathol Exp Neurol, 54:276-281.

[69] Bauer J, Strauss S, Schreiter-Gasser U, Ganter U, Schlegel P, Witt I, et al (1991). Interleukin-6 and alpha-2macroglobulin indicate an acute-phase state in Alzheimer's disease cortices. FEBS Lett, 285:111-114.

[70] Tarkowski E, Blennow K, Wallin A, and Tarkowski A (1999). Intracerebral Production of tumor necrosis factoralpha, a local neuroprotective agent, in Alzheimer disease and vascular dementia. J Clin Immunol, 19:223-230.

[71] van der Wal EA, Gomez-Pinilla F, and Cotman CW (1993). Transforming Growth factor-beta1 is in plaques in Alzheimer and down pathologies. Neuroreport, 4:69-72.

[72] Sheng JG, Mrak RE, Bales KR, Cordell B, Paul SM, Jones $\mathrm{RA}$, et al (2000). Over expression of the neuritotrophic cytokine S100 beta precedes the appearance of neuritic beta-amyloid plaques in APPV717F mice. J Neurochem, 74:295-301. 